\title{
Spatial and Temporal Variations of Atmospheric Turbidity and Related Parameters in Niger
}

\author{
A. BEN MOHAMED AND J.-P. FRANGI* \\ Université de Niamey, Faculté des Sciences, Département de Physigue, Niamey, Niger \\ J. Fontan AND A. DRUILHeT \\ Laboratoire d'Aérologie, Université de Toulouse, Toulouse, France
}

(Manuscript received 28 August 1991, in final form 30 January 1992)

\section{ABSTRACT}

\begin{abstract}
Spectral aerosol optical depths were measured in seven localities of Niger (West African Sahel) from February 1986 to June 1987. Results of these observations, together with related climatic parameters, are presented and discussed in this paper.
\end{abstract}

\section{Introduction}

In previous papers (Ben Mohamed and Frangi 1983, 1986 , hereafter referred to as BMF1 and BMF2), results of extensive measurements of atmospheric turbidity and related parameters in Niamey (Niger) were reported. The present paper gives results obtained from a network of transmissometers in seven localities of Niger.

Among the objectives of this study, first is the desire to provide information on the atmospheric optical quality as it may relate to the remote sensing and climatological description of this area (Lare and Nicholson 1990); second, is to foresee a description of dusttransport mechanism over Niger and its contribution to West African dust plumes. It is worth mentioning that this country covers an area of $1200000 \mathrm{~km}^{2}$ and is located in one of the major mineral dust-production regions of the globe (Pewe 1981).

\section{a. Network stations}

Figure 1 presents the stations where measurements were done from February 1986 to June 1987. Except for Niamey, all observations were made at local meteorological stations located at airports built on lateritic hills. Observations in Niamey were done at the university campus situated in a sandy area along the river Niger.

\footnotetext{
- Current address: CRPE, CNET-CNRS, 92131 lssy-les-Moulineaux, France.

Corresponding auchor address: Dr. A. Ben Mohamed, Universite de Niamey, Faculte des Sciences, Department de Physique, Niamey, BP 10662 Niger.
}

The population of the different localities are the following: Niamey-400 000 inhabitants, Birni N'Konni-250 000, Zinder-120000, Agadez and Tahoua-50000 each, N'Guigmi-30000, and Bilma-10 000. In Fig. 1 it can also be seen that two stations, Agadez and Bilma, are in fact in the Saharan part of Niger. Tahoua represents a transition between this part and the southern, more agricultural part of the country. The mean annual rainfall is $10 \mathrm{~mm}$ for Bilma, $120 \mathrm{~mm}$ for Agadez, $400 \mathrm{~mm}$ for Tahoua, 500 $\mathrm{mm}$ for Niamey and Birni N'Konni, $450 \mathrm{~mm}$ for Zinder, and $200 \mathrm{~mm}$ for N'Guigmi.

At all stations were recorded solar transmissions at different wavelengths, air temperature, relative humidity, dewpoint temperature, wind speed and direction, pressure, visibility, and ground skin temperature. This last parameter, which is not measured at meteorological stations, was obtained from a thermometer set on the ground and is reported or not depending on the availability of extra thermometers at the station. As mentioned before, transmission measurements in Niamey were done on the university campus, together with ground skin-surface temperature. The other parameters were collected from the airport meteorological station, located approximately $8 \mathrm{~km}$ from the campus.

Table 1 indicates for each measuring site the different wavelengths used for solar transmission measurements. The measurements were made daily under cloud-free conditions at 0900,1200, and 1500 UTC. Except for Bilma, the calibration of the instruments was checked once every four months. No significant variation of the calibration constants and no deterioration of the transmission filters were observed during the 17-month period. It is worth mentioning that all instruments were Volz or Volz-type sunphotometers, that is, with mi- 


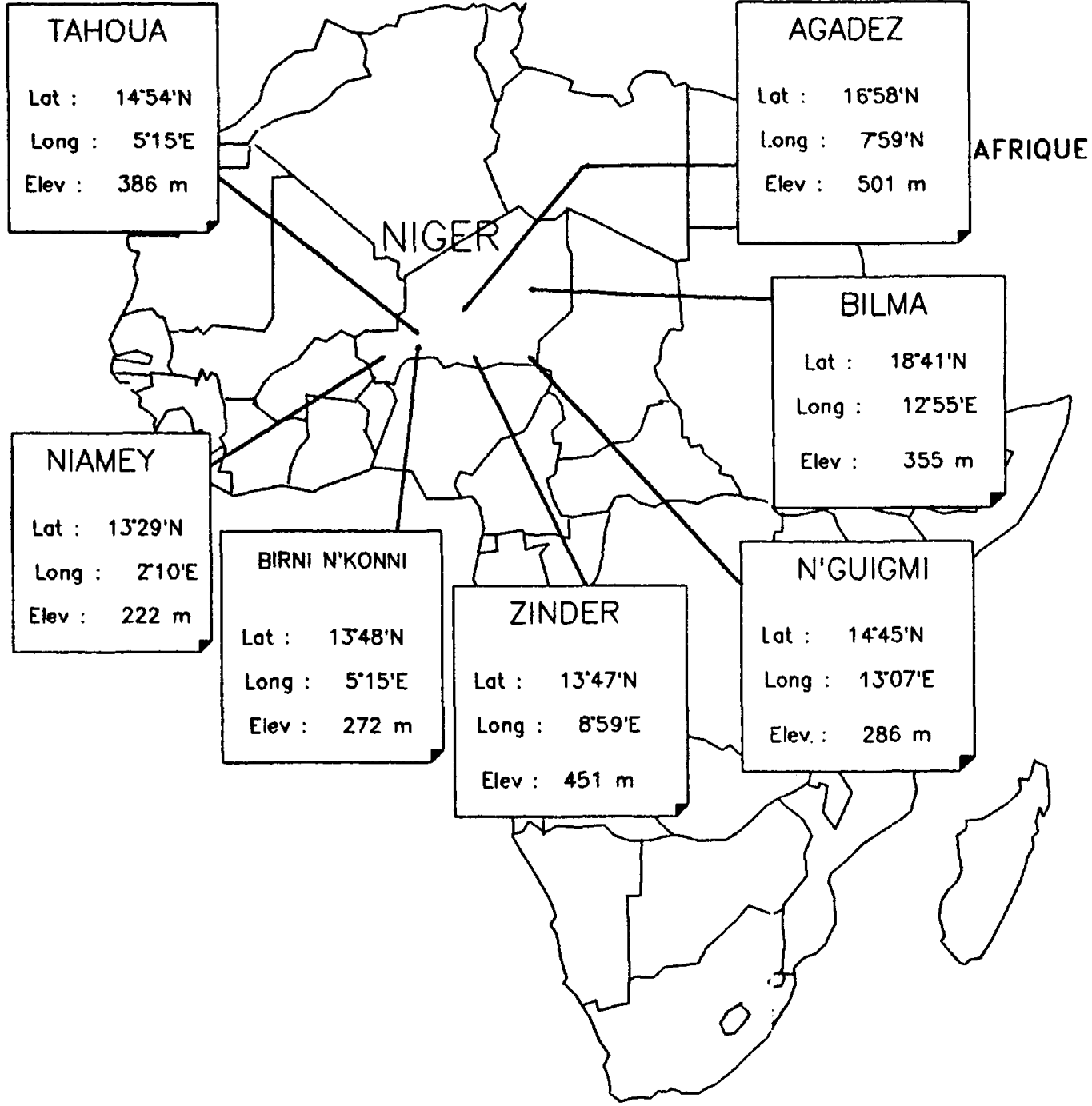

FIG. 1. Network stations.

croammeter reading. Any lack of measurements was essentially due to battery failure and the instrument had then to be shipped back to Niamey.

\section{b. Climatological features of network stations}

Figures 2a-g present climatological features of the seven sites. The plotted curves represent, averaged over
30 years (1951-80), decadic means of maximal and minimal air temperature, relative humidity, and total precipitation for the seven sites. One may note that air temperature almost exhibits two maxima during the year (April and October), whereas relative humidity and total precipitation present well-known shapes for this region, as already mentioned in BMF1 when addressing the total precipitable water in Niamey.

TABLE 1. Wavelengths used for solar transmission measurements at each site.

\begin{tabular}{|c|c|c|c|c|c|c|c|c|c|c|c|}
\hline \multirow[t]{2}{*}{ Stations } & \multicolumn{11}{|c|}{ Wavelengths (nm) } \\
\hline & 350 & 380 & 500 & 610 & 640 & 748.7 & 873 & 876 & 945 & 1040 & 1610 \\
\hline Niamey & $*$ & $*$ & $*$ & $*$ & $*$ & $*$ & $*$ & $*$ & $*$ & $*$ & * \\
\hline Birni & * & $*$ & * & & * & & & $*$ & $*$ & & \\
\hline Tahoua & & $*$ & $*$ & $*$ & & $*$ & 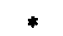 & & & $*$ & \\
\hline Agadez & & $*$ & $*$ & $*$ & & $*$ & $*$ & & $*$ & $*$ & \\
\hline Zinder & & $*$ & $*$ & $*$ & & $*$ & $*$ & & $*$ & $*$ & \\
\hline N'Guigmi & & $*$ & $*$ & $*$ & & * & $*$ & & * & $*$ & \\
\hline Bilma & & $*$ & $*$ & * & & * & $*$ & & * & * & \\
\hline
\end{tabular}


NIAMEY

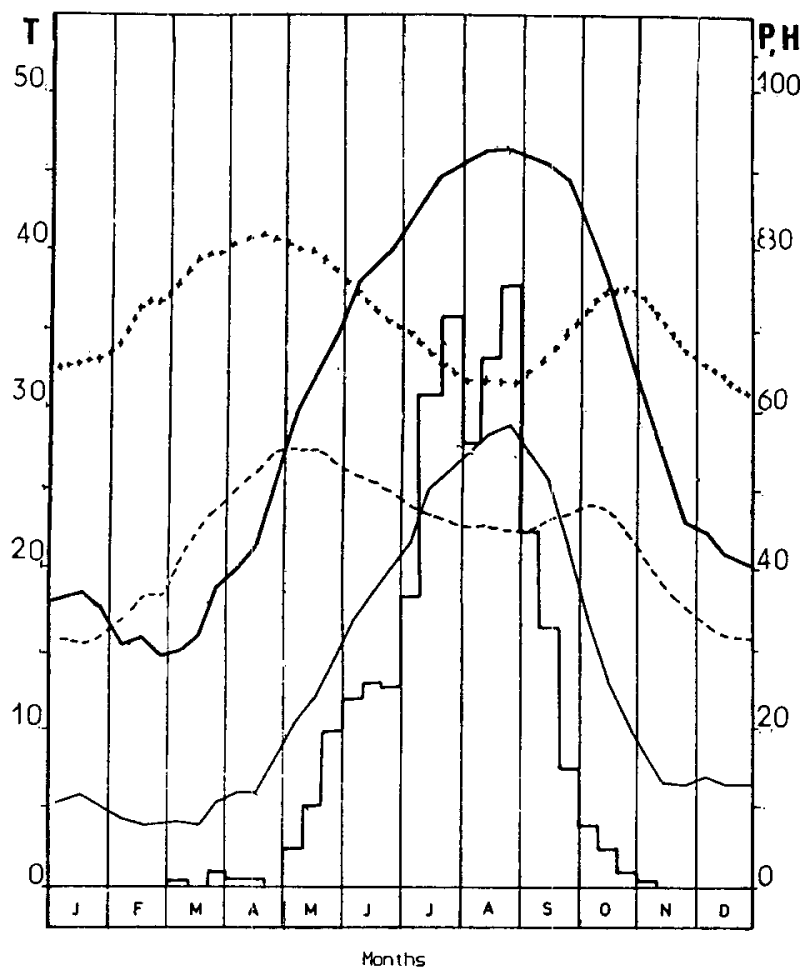

ZINDER

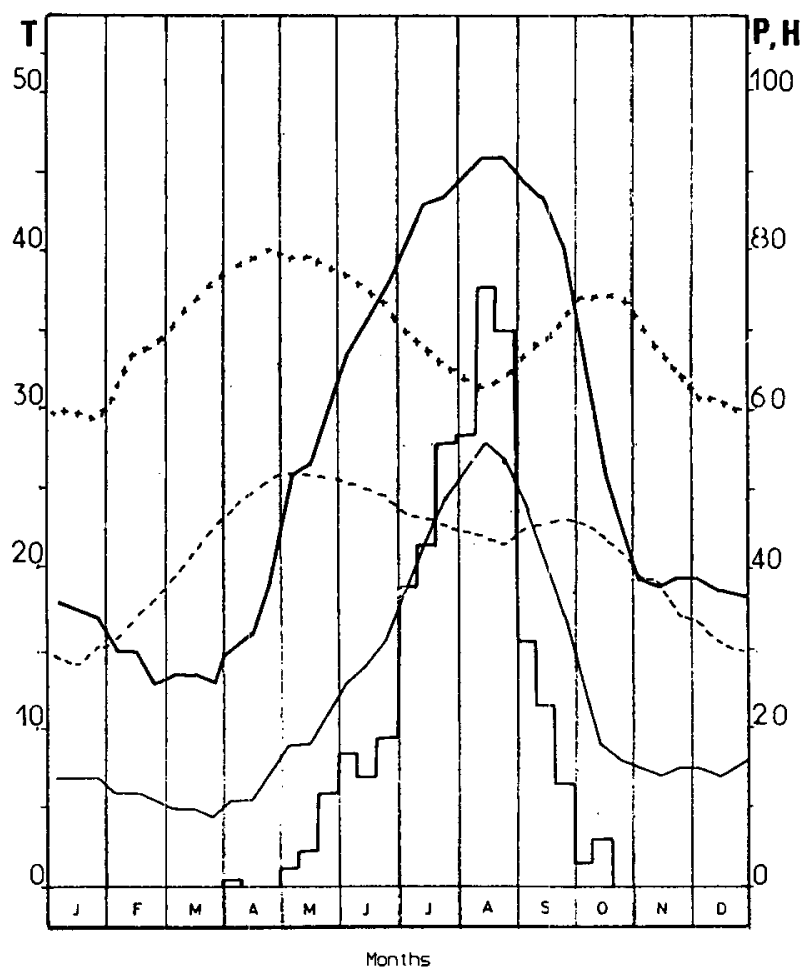

BIRNI N'KONNI

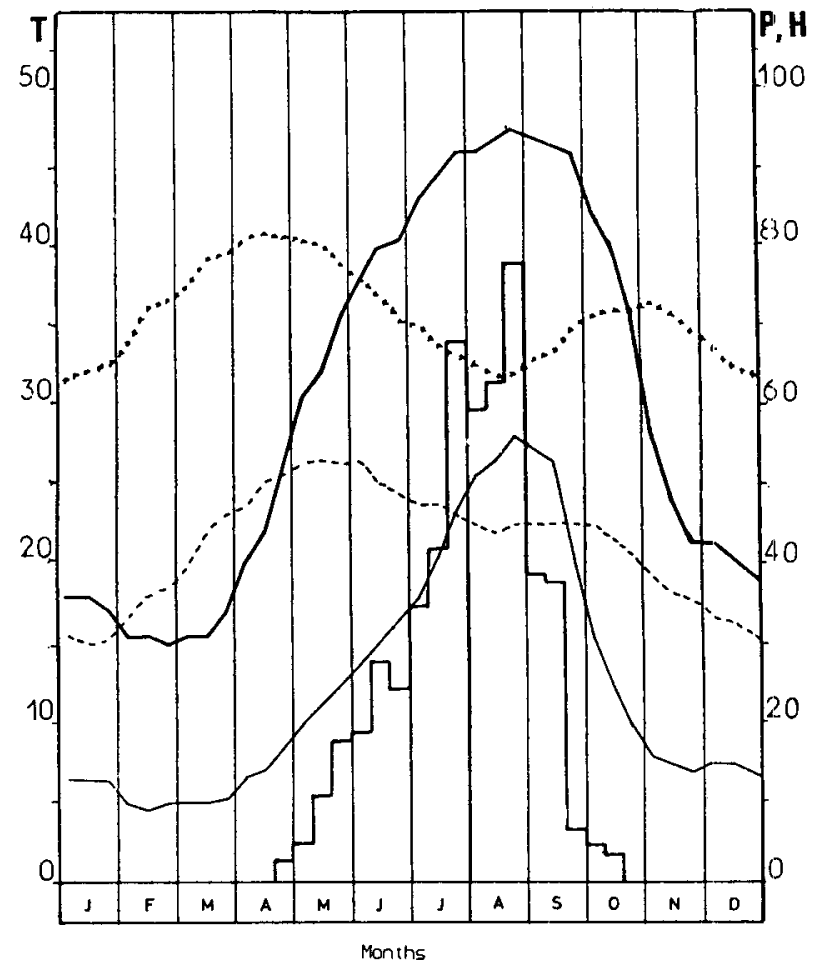

FIG. 2. (a)-(g): Averaged over 30 years decadic means of maximal (x x) and minimal (- - ) air temperature $T\left({ }^{\circ} \mathrm{C}\right)$, maximal (- - ) and minimal $(\longrightarrow)$ relative humidity $H(\%)$, and total precipitation

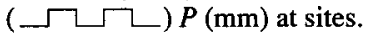


N'GUIGMI

TRAOA
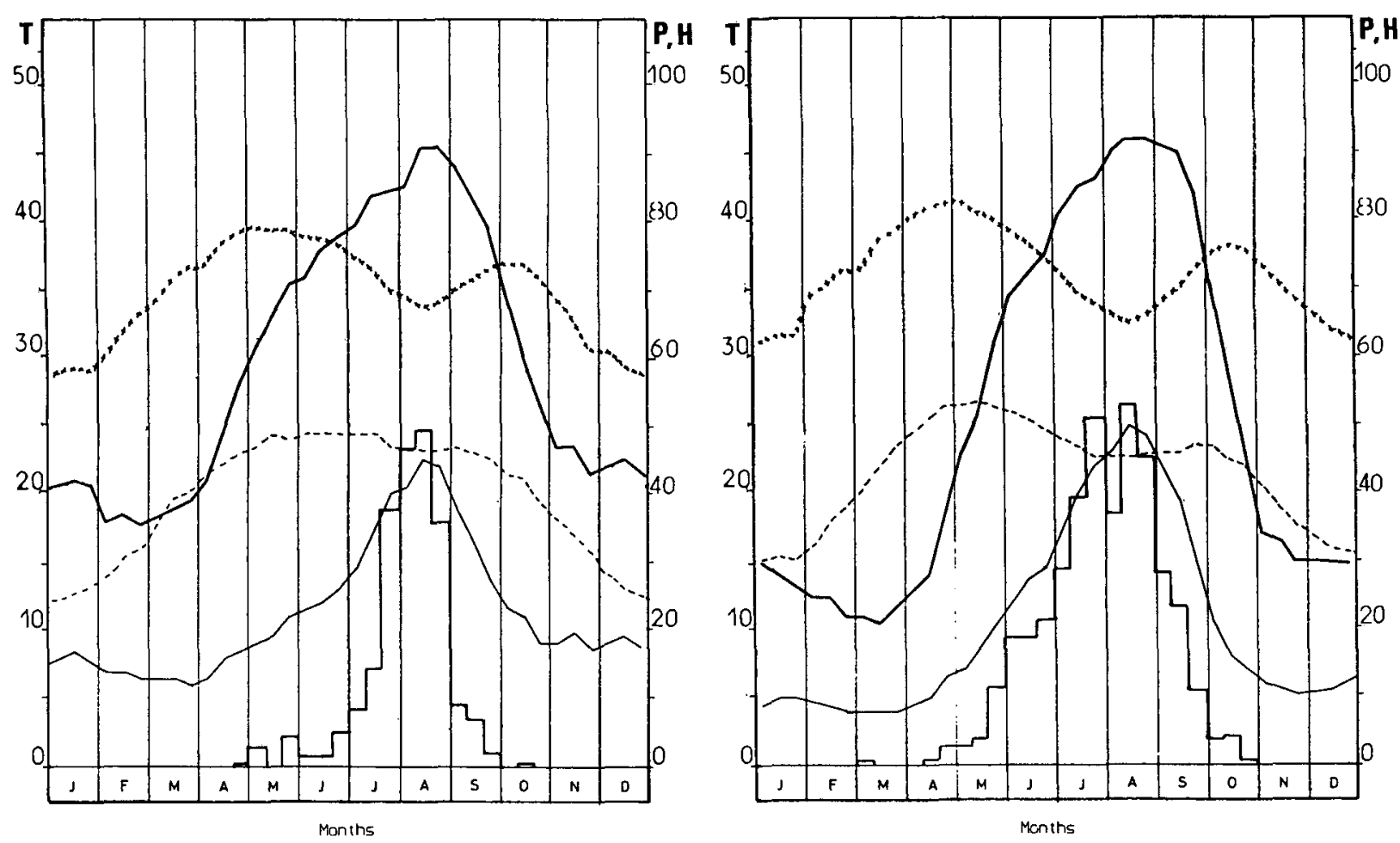

AGADE2

BILMA
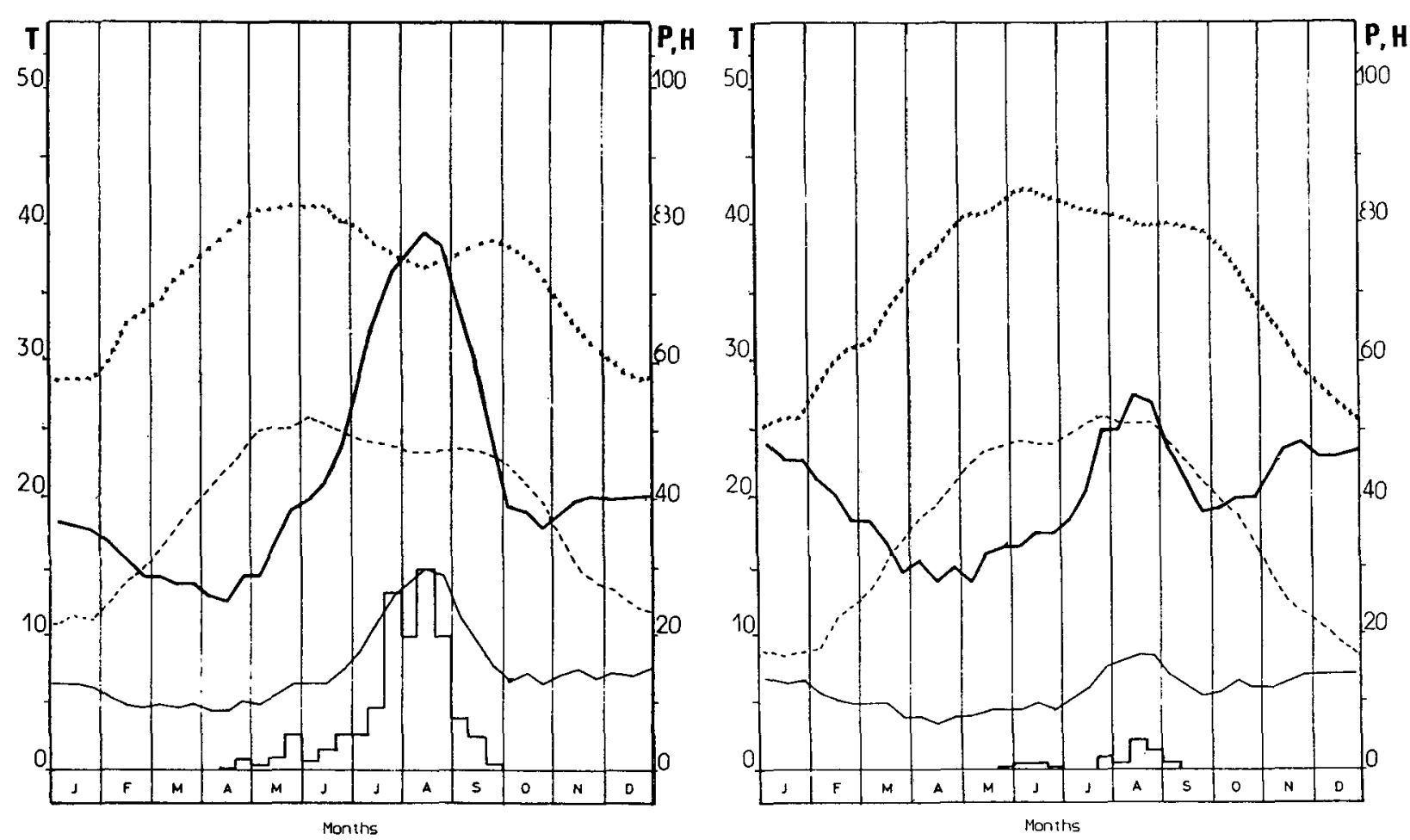

FIG. 2. (Continued) 

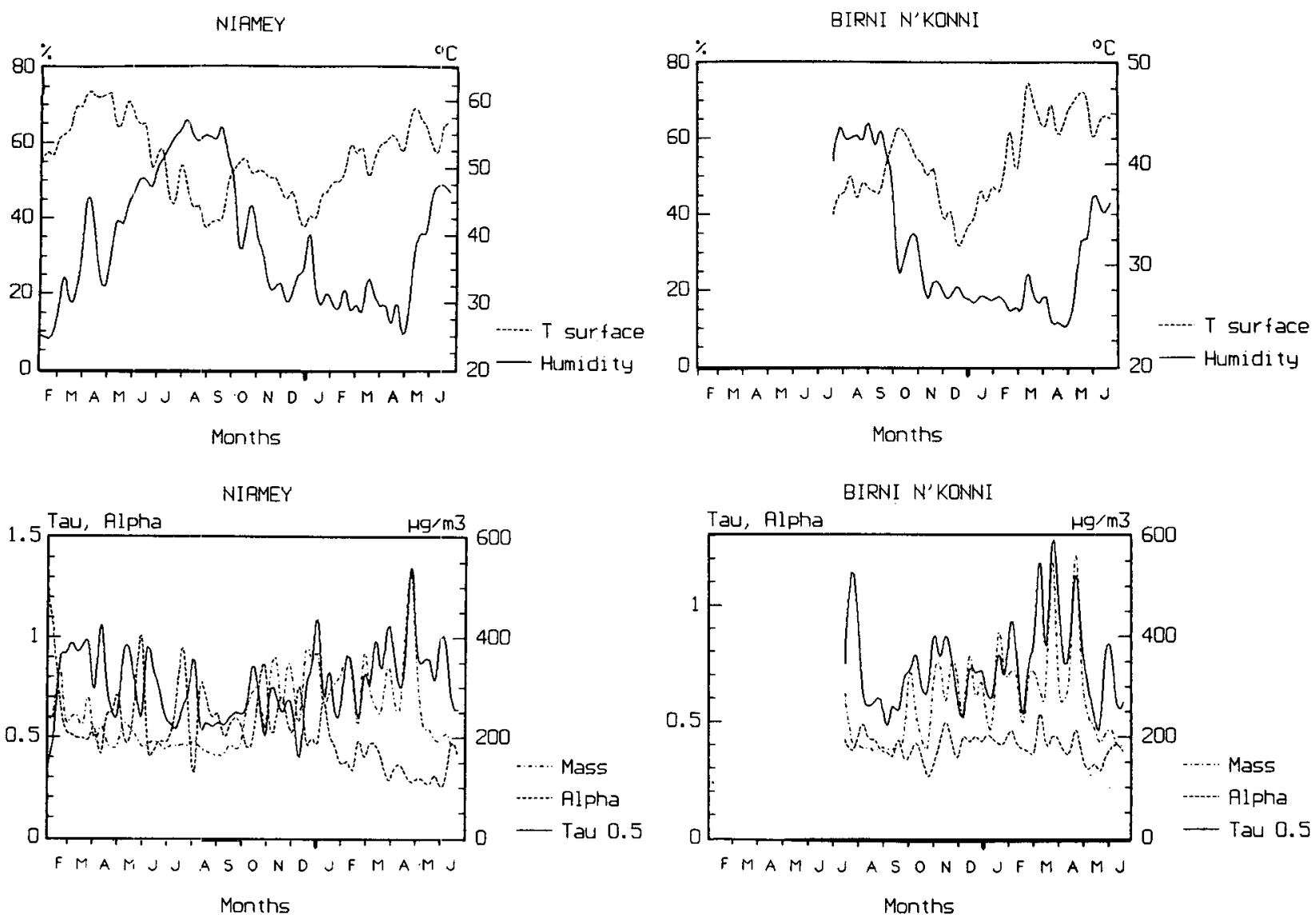

Fig. 3. (a)-(g): Weakly mean values of ground skin temperature Ts, relative humidity $H$, mass concentration (mass), Ångström wavelength exponent $\alpha$ (alpha), and aerosol optical thickness at $500 \mathrm{~nm}$ (tau 0.5) versus months (from February 1986 to June 1987) at sites.

\section{Results}

Figure $3 \mathrm{a}-\mathrm{g}$ presents the variation of weekly mean values of the following parameters at 1200 UTC: ground skin temperature, relative humidity, mass concentration, Ångström wavelength exponent alpha, and aerosol optical thickness at $500 \mathrm{~nm}$, versus months (from February 1986 to June 1987), for each site. Data on ground skin temperature are reported here for information, due to the importance of this quantity in remote sensing of the energy budget. We shall now discuss the other parameters.

\section{a. Relative humidity $H$}

This parameter shows for almost all sites the same seasonal pattern (i.e., low values in the dry season and higher in the humid), which was discussed in BMF1 where relationships were established between precipitable-water content and dewpoint temperature, and between this last quantity and the northern position of the intertropical discontinuity in Niamey. The only irregularities from an obvious general pattern are observed at Niamey and Bilma. The peaks observed at
Bilma are associated with rainy events at this station. Concerning Niamey, the peaks observed are related to a trade-wind air mass generally oriented north-northwest-north-northeast between February and March.

It can also be seen that stations at the same latitudinal position exhibit almost the same pattern for $H$, so that for this parameter an annual pattern for each latitude in this region can easily be derived. The minimum of $H$ is observed at Zinder and appears to be below $10 \%$.

\section{b. Aerosol optical thickness at $500 \mathrm{~nm}$ (tau 0.5)}

The spectral aerosol optical thickness was computed in the usual way, that is,

$$
\tau a_{\lambda}=\tau t_{\lambda}-\left(\tau R_{\lambda}+\tau \mathrm{O}_{3}\right)
$$

where $\tau t_{\lambda}$ is the total spectral optical thickness of the atmosphere, $\tau R_{\lambda}$ is the Rayleigh or molecular scattering optical depth (Penndorf 1957), and $\tau 0_{3}$ is the optical depth arising from absorption by the atmospheric ozone evaluated by assuming a constant midlatitude concentration (Junge 1963) and absorption coefficients given by Inn and Tanaka (1959). 


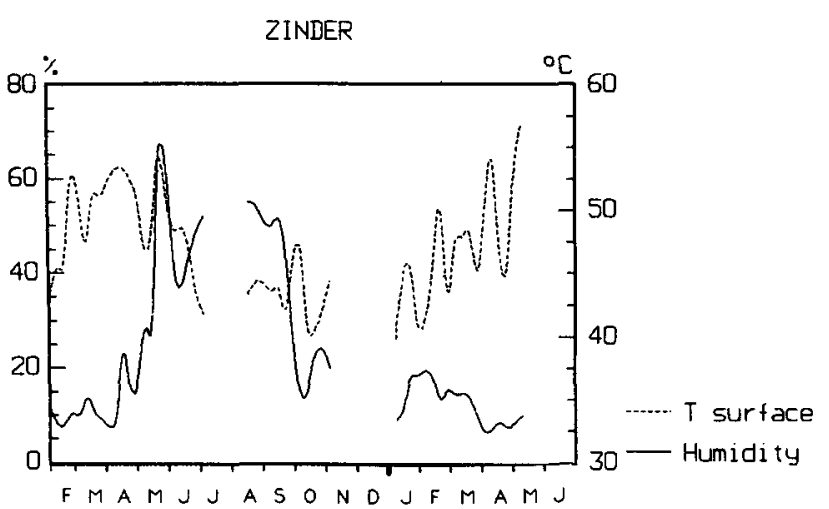

Months

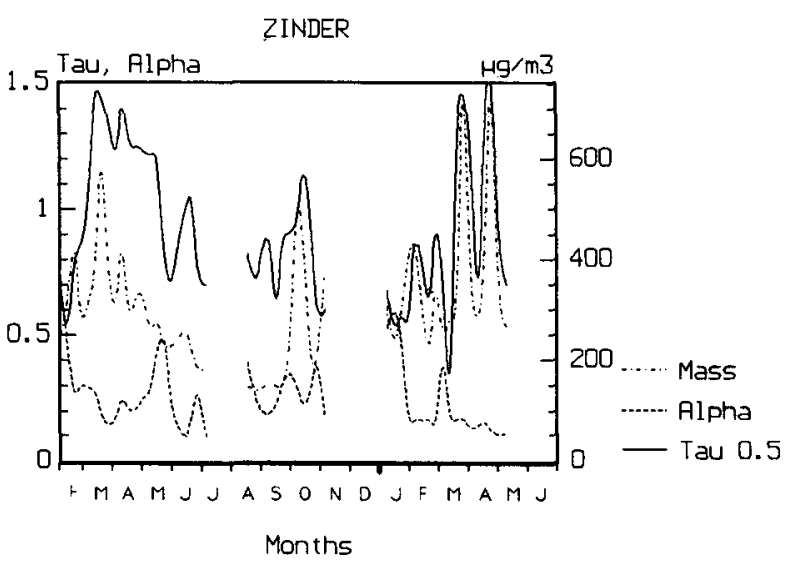

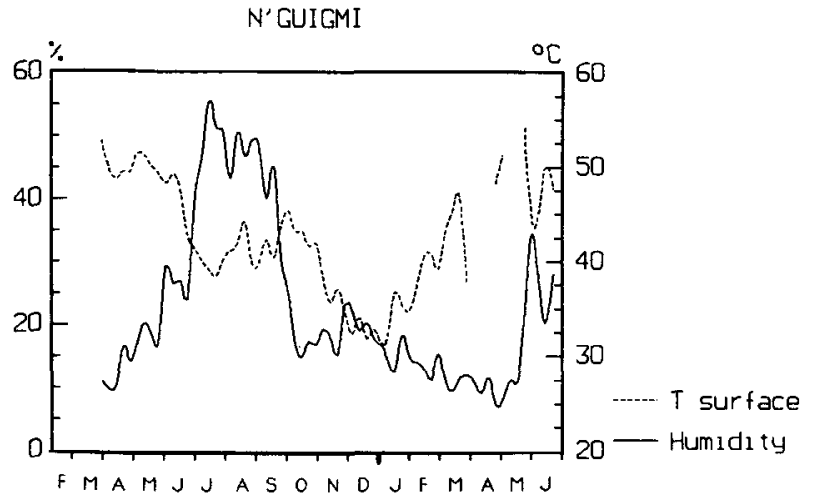

Months

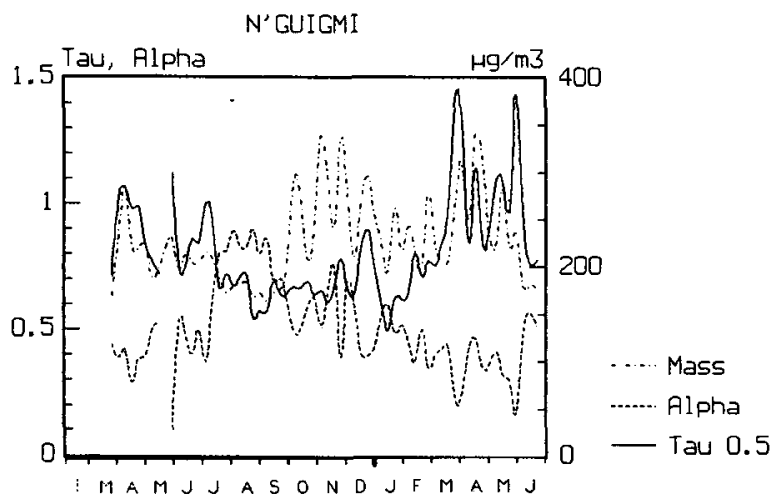

Months

FIG. 3. (Continued)

Errors in determination of $\tau a_{\lambda}$ were computed according to

$$
\Delta \tau a_{\lambda}= \pm\left(m^{-1}\left|\Delta I_{\lambda} / I_{\lambda}\right|+m^{-1}\left|\Delta I_{0 \lambda} / I_{0 \lambda}\right|+\Delta \tau 0_{3}\right)
$$

with $\tau a_{\lambda}$ in the form:

$$
\tau a_{\lambda}=m^{-1} \ln \left(I_{0 \lambda} / S I_{\lambda}\right)-\left(\tau R_{\lambda}+\tau \mathrm{o}_{3}\right)
$$

where

$I_{0 \lambda}$ : the reading the transmissometer would have outside the atmosphere;

$I_{\lambda}:$ the under-atmosphere reading of the instrument;

$S:$ a correction factor that depends on solar distance;

$m: \quad$ air mass.

Assuming a reading error of $1 \%$, minimum and maximum values of $\Delta \tau a_{\lambda}$ observed for the period under investigation are reported in Table 2 . Because the instruments are carried out only when measurements have to be performed, no temperature correction of the data has to be done.

We chose to present the aerosol optical thickness at $500 \mathrm{~nm}$ because this wavelength has been strongly rec- ommended by WMO (1978) and is also the most frequently reported by different authors, so that measurements done under different climatic conditions can be compared. The multispectral data are to be used for inferring aerosol-size distributions as done in BMF2, for the study of regional dust transport now undertaken.

The values obtained for the aerosol optical thickness at $500 \mathrm{~nm}$ on this regional scale confirm the comment in BMF2 concerning the order of magnitude of this parameter in this area as compared to published data from other places (Flowers et al. 1969; Polavarapu 1978; King et al. 1980); namely, that in this region these values can be ten times higher than those reported by these authors. It is worthwhile to mention that for Niamey seasonal variations of this quantity were almost identical to those presented in BMF2.

For all stations it can be noted that the high values of this quantity are observed mainly during the dry season (low relative humidity), where maxima can reach 1.5. This indicates that the major contribution to aerosol optical thickness in this region is from dust.

It is important to note that no similarity can be observed in the patterns for the different sites reported in this study, which indicates that there does not exist an easily located source of dust in this region contributing 


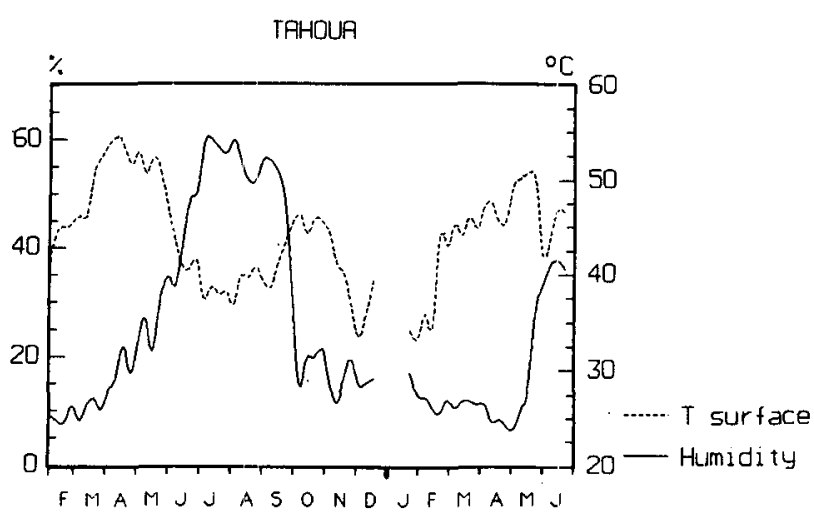

Months

TPHOUA

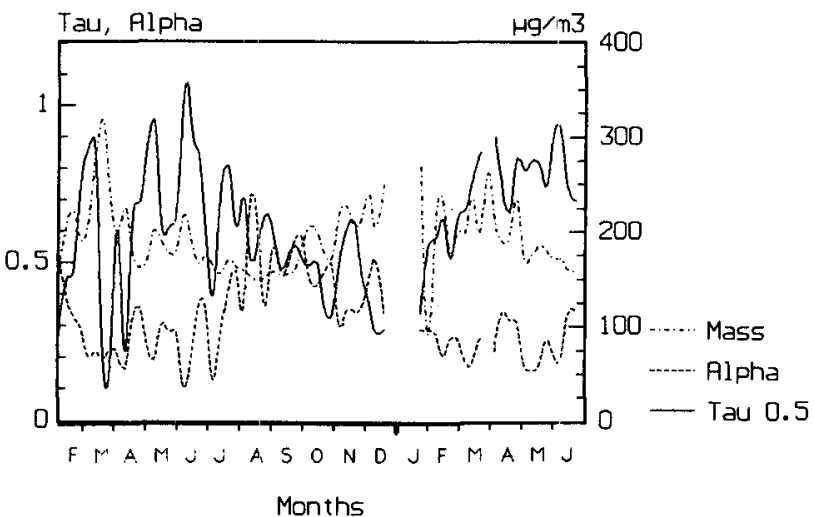

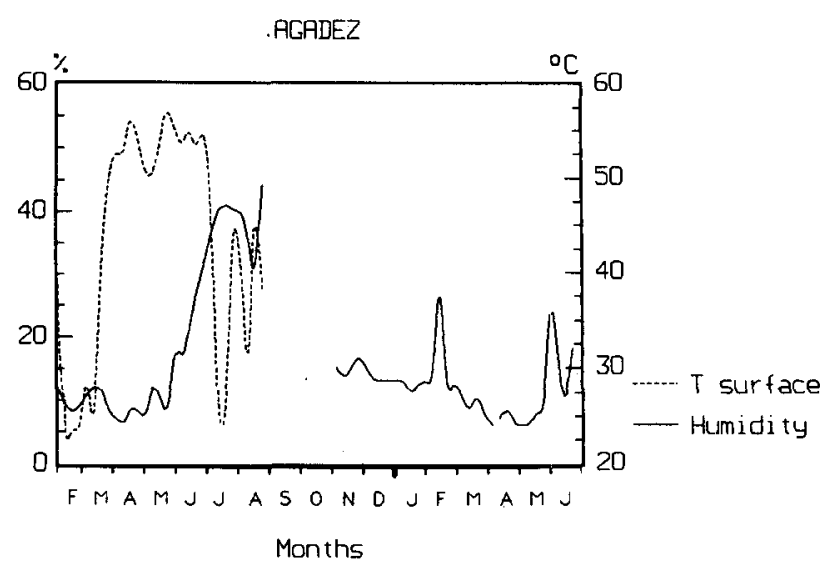

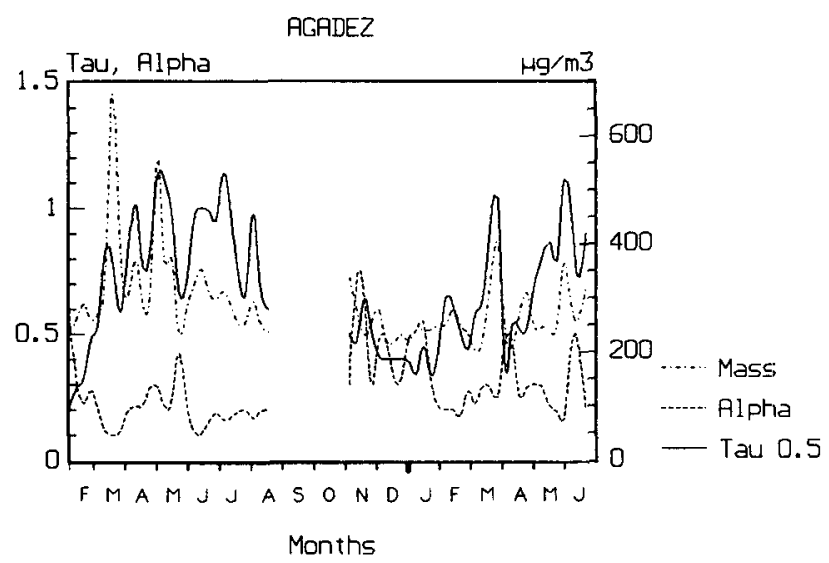

Months

FIG. 3. (Continued)

to West African plumes. On the other hand, one observes almost identical variations during some periods for four stations located nearly at the same latitude, namely, N'Guigmi, Zinder, Birni N'Konni, and Niamey.

\section{c. Angström wavelength exponent (alpha)}

This parameter has been derived by best fitting of spectral aerosol optical thicknesses as described by Tomasi (1982). The Ångström empirical relationship

$$
\tau a_{\lambda}=\beta \lambda^{-\alpha}
$$

relates the spectral aerosol optical thicknesses $\tau a_{\lambda}$ to the Ångström turbidity coefficient $\beta$ and the wavelength exponent $\alpha$.
As is well known (Junge 1963), this parameter is closely related to the size distribution of the suspended aerosol. The results presented here indicate that, as far as the order of magnitude is concerned, the values for N'Guigmi and Zinder in the humid season (June-September) are extreme ( 0.85 and 0.20 , respectively). Zinder shows during that period quite the lowest values of this quantity among the network, so as to indicate that even in the rainy season dust generation can occur in this area, as we shall see later when addressing the total mass of airborne particulate matter. On the other hand, for N'Guigmi, this seems not to be the case; that is, the atmosphere of this area once washed out by the first rains is no more affected by dust.

In the dry season, on the other hand, quite close values for $\alpha$ are noted (between 0.2 and 0.4 ), regardless

TABLE 2. Minimum and maximum values of $\Delta \tau a_{\lambda}$.

\begin{tabular}{|c|c|c|c|c|c|c|c|c|c|c|}
\hline$\lambda(\mathrm{nm})$ & 350 & 380 & 500 & 610 & 641 & 748.7 & 873 & 876 & 1040 & 1610 \\
\hline$\Delta \lambda(\mathrm{nm})$ & 10 & 11 & 10 & 10 & 10 & 10 & 10 & 17 & 10 & 20 \\
\hline $10^{2} \Delta I_{0 \lambda} / I_{0}$ & 7 & 3 & 4 & 9 & 2 & 4 & 4 & 2 & 7 & 4 \\
\hline $10^{2} \Delta \tau a_{\lambda}$ & $7-19$ & $6-18$ & $7-16$ & $10-20$ & $3-13$ & $9-21$ & $8-25$ & $3-9$ & $6-15$ & $5-10$ \\
\hline
\end{tabular}



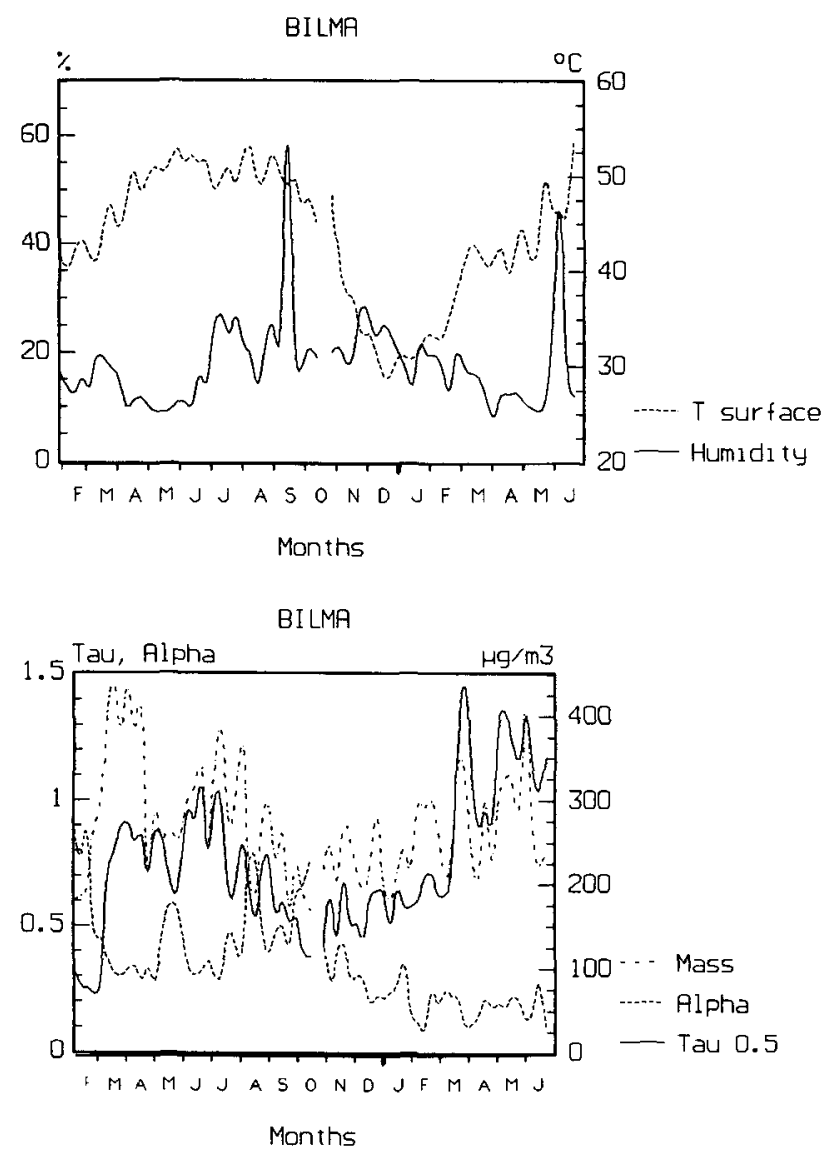

FIG. 3. (Continued)

of the area. Niamey exhibits some particularities related to pollution over a populated and industrialized area.

Considering all $\alpha$ values obtained during the 17month period under investigation, one ends up with percentages of $\alpha<1.3$ varying between $85 \%$ and $97 \%$ for the seven sites. As 1.3 is the generally admitted default value of the Ångström wavelength exponent, care must be taken when using it for any prediction in this region.

\section{d. Total mass of airborne particulate matter (mass)}

This quantity was obtained by converting visibility to mass using the relation obtained for Niamey in BMF2:

$$
M=\frac{1339.84}{V^{0.67}}
$$

with $M$ expressed in micrograms per cubic meter, and visibility $V$ in kilometers.

As mentioned by Patterson and Gillette (1977), the exponent in the preceding expression is closely related to the mass distribution. As seen in section 2.c, the values for the Ångström wavelength exponent $\alpha$ are quite close, regardless of locality, in the dry season, so that one can reasonably estimate total mass over this area during that season using the preceding relation.

In the humid season, on the other hand, the low values for mass concentration are indicative only because of the lack of precision in estimating high visibilities at meteorological stations. Zinder also shows high mass-concentration values during the humid season, confirming the observed behavior of the Ångström wavelength exponent at this site. It is worth mentioning again almost identical variations during some periods for four stations located nearly at the same latitude, namely, N'Guigmi, Zinder, Birni N'Konni, and Niamey.

Finally, it can be seen that the mass-concentration values in the desert area of Bilma are not the highest, which weakens the hypothesis advanced by Kalu (1979) of this area as being a major source of dust in West Africa. Maxima are observed at Zinder (more than $700 \mu \mathrm{g} \mathrm{m}^{-3}$ ).

\section{Conclusions}

In this paper we have presented spatial and temporal variations of atmospheric turbidity and related climatological parameters in Niger. These results confirm and expand those already presented in BMF1 and BMF2. It appears that it is not possible to speak of a potentially well-localized dust source in this region. A reasonable regional dust transport model may therefore be possible only if the transport mechanism is understood on synoptic scale such as Niger. This study is now being undertaken.

The Sahel constitutes a prime target for remote sensing by satellite owing to its great homogeneity and its relatively simple climatic feature, but it is necessary to validate these observations with ground informations that can be obtained from dense grid network such as the one presented here.

Acknowledgments. The authors wish to thank Brent N. Holben of Laboratory of Terrestrial Physics, NASA/ GFSC, Greenbelt, Maryland, for kindly furnishing some of the transmissometers used in this study. La Direction de la Météorologie Nationale du Niger is acknowledged for surface and upper-air data.

\section{REFERENCES}

Ben Mohamed, A., and J.-P. Frangi, 1983: Humidity and turbidity parameters in Sahel: A case study for Niamey (Niger). $J$. Climate Appl. Meteor., 22, 1820-1823.

- , and - 1986: Results from ground-based monitoring of spectral aerosol optical thickness and horizontal extinction: Some specific characteristics of dusty Sahelian atmospheres. J. Climate Appl. Meteor., 25, 1807-1815.

Flowers, E. C., K. R. Kurfis, and R. A. Mc Cormick, 1969: Atmospheric turbidity over the United States, 1961-1966. J. Appl. Meteor., 8, 955-962.

Inn, E. C. Y., and Y. Tanaka, 1959: Ozone absorption coefficients in visible and ultraviolet regions. Adv. Chem. Ser., 263-268.

Junge, C. E., 1963: Air Chemistry and Radioactivity. Academic Press, $382 \mathrm{pp}$. 
Kalu, A. E., 1979: The African dust plume: Its characteristics and propagation across West Africa in winter. Saharan Dust, SCOPE 14, C. Morales, Ed., Wiley, 95-118.

King, M. D., D. M. Byrne, J. A. Reagan, and B. M. Herman, 1980: Spectral variations of optical depth at Tucson, Arizona, between August 1975 and December 1977. J. Appl. Meteor., 19, 723732.

Lare, A. R., and S. E. Nicholson, 1990: A climatonomic description of the surface energy balance in the central Sahel. Part I: shortwave radiation. J. Appl. Meteor., 29, 123-137.

Patterson, E. M., and D. A. Gillette, 1977: Measurements of visibility vs mass concentration for airborne soil particles. Atmos. Environ., 2, 193-196.
Pendorf, R., 1957: Table of the refractive index for standard air and the Rayleigh scattering coefficient for spectral region between 0.2 and $20.0 \mu \mathrm{m}$ and their application to atmospheric optics. $J$. Opt. Soc. Amer., 47, 176-182.

Pewe, T. L., 1987: Desert dust: An overview. Desert Dust: Origin, Characteristics and Effects on Man. Special paper 186, T. L. Pewe, Ed. Geological Society of America, 1-10.

Polavarapu, R. J., 1978: Atmospheric turbidity over Canada. J. Appl. Meteor., 17, 1368-1374.

Tomasi, C., 1982: Features of the scale height for particulate extinction in hazy atmospheres. J. Appl. Meteor., 21, 931-944.

WMO, 1978: International operation handbook for measurement of background atmospheric pollution. WMO No. 491, 10-20. 